\title{
Effects of Social Support Visibility on Adjustment to Stress: Experimental Evidence
}

\author{
Niall Bolger \\ Columbia University
}

\author{
David Amarel \\ New York University
}

\begin{abstract}
Previous fieldwork has suggested that visible social support can entail an emotional cost and that a supportive act is most effective when it is accomplished either (a) outside of recipients' awareness or (b) within their awareness but with sufficient subtlety that they do not interpret it as support. To investigate the latter phenomenon, the authors conducted 3 experiments in which female participants were led to expect a stressful speech task and a confederate peer provided support in such a way that it was either visible or invisible $(N=257)$. Invisible support (practical and emotional) reduced emotional reactivity relative to visible and no support. Visible support was either ineffective or it exacerbated reactivity. Explanatory analyses indicated that support was effective when it avoided communicating a sense of inefficacy to recipients.
\end{abstract}

Keywords: relationships, social support, mental health, stress and coping, process analysis

Although the need for social relationships is considered fundamental to human psychology (Baumeister \& Leary, 1995; Reis, Collins, \& Berscheid, 2000) and the presence and quality of these relationships is essential to physical and psychological well-being (Berkman, 1995; Berkman, Glass, Brissette, \& Seeman, 2000; S. Cohen, 1992; Stroebe \& Stroebe, 1996; Uchino, Cacioppo, \& Kiecolt-Glaser, 1996), one of the more persistent puzzles has been how to explain these beneficial effects. On the one hand, there is ample evidence that people with larger social networks and those who perceive that support is available to them show less reactivity to stressors or have better health (S. Cohen \& Wills, 1985; House, Landis, \& Umberson, 1988; House, Umberson, \& Landis, 1988). On the other hand, studies investigating whether concrete acts of support explain these beneficial effects have produced disappointing results (Barrera, 1986; Bolger, Zuckerman, \& Kessler, 2000; Coyne \& Bolger, 1990). Although there are exceptions (e.g., Abraido-Lanza, 2004; N. L. Collins, Dunkel-Schetter, Lobel, \& Scrimshaw, 1993; Feldman, Downey, \& Schaffer-Neitz, 1999), most studies have found null or adverse relations between the receipt of support and adjustment.

Various mechanisms could explain this discrepancy in findings, such as miscarried helping (Coyne, Wortman, \& Lehman, 1988; Martire, Stephens, Druley, \& Wojno, 2002; Newsom \& Schulz, 1998); feelings of indebtedness or inequity following support receipt (Gleason, Iida, Bolger, \& Shrout, 2003); reverse causation, that is, poorer adjustment leading to increased support receipt (Seidman, Shrout, \& Bolger, 2006); or unmeasured stressor sever-

Niall Bolger, Department of Psychology, Columbia University; David Amarel, Department of Psychology, New York University.

This research was supported in part by National Institute of Mental Health Grant MH60366. The data were collected by David Amarel in partial fulfillment of master's and doctoral degree requirements for the Graduate School of Arts and Science, New York University.

Correspondence concerning this article should be addressed to Niall Bolger, Department of Psychology, Columbia University, 406 Schermerhorn Hall, New York, NY 10027. E-mail: bolger@psych.columbia.edu ity acting as a third variable, that is, stressor severity leading to both poorer adjustment and increased support receipt (Barrera, 1986; Bolger \& Eckenrode, 1991; Seidman et al., 2006). Given the likely complexity and variety of supportive interactions, it is unlikely that any single mechanism will provide a sufficient account. Evidence for a particular mechanism, however, was found in a daily diary study of dyads under stress (Bolger et al., 2000), namely, that support attempts by providers that were unacknowledged by recipients were the most effective in reducing distress (see also Shrout, Herman, \& Bolger, 2006, for a broader set of analyses of the same dataset). Bolger et al. (2000) interpreted these results as showing that support attempts can be beneficial, that awareness of them can entail an emotional cost, and that at least some forms of skillful support are accomplished in a way that is not noticed or interpreted as support by recipients.

Although the diary study evidence bolstered the notion that what Bolger et al. (2000) called invisible support was superior to visible support, the results of this nonexperimental field study were not immune to rival interpretations. The current article reports on the next step in this program of research, in which we sought to refine our thinking about the invisible support phenomenon and to bring it, if possible, under experimental control in a laboratory setting. We also sought to use the greater control afforded by a laboratory setting to isolate factors that might mediate the effect.

\section{Perceived, Received, and Invisible Support}

Given the consistent evidence that social support availability protects people from the effects of stressors (S. Cohen, 1992; S. Cohen \& Wills, 1985; Hobfoll \& Vaux, 1993; Stroebe \& Stroebe, 1996; Wills, 1991), it might seem reasonable to suppose that people who are integrated into social networks or who perceive that support is available to them make effective use of this support in times of stress. Research over the past 2 decades, however, has not only failed to show that such people mobilize support under stress (Dunkel-Schetter \& Bennett, 1990; Lakey \& Drew, 1997; Wethington \& Kessler, 1986) but has failed as well to show that received support is consistently beneficial in such situations (Bar- 
rera, 1986; Bolger et al., 2000; Coyne \& Bolger, 1990). For example, Helgeson (1993) found that perceived available support had a beneficial effect on adjustment to heart attacks, whereas received support from significant others appeared to have a harmful effect. Frazier, Tix, and Barnett (2003), in two recent studies of kidney transplant patients, found no link between supportive behaviors by significant others and patient distress.

There are a number of plausible reasons why received support may be detrimental or at least ineffective in some situations. First, researchers on health-related caregiving have found that a substantial proportion of recipients receiving care from spouses complain of feeling overly dependent on and indebted to the spouse (Newsom, 1999). Second, researchers have shown that inequities in received support, namely, feeling overbenefited, can lead to increased distress (e.g., Gleason et al., 2003). Third, experimental work has shown that receiving help can have detrimental emotional effects. In reviewing this literature, Fisher, Nadler, and Whitcher-Alagna (1982) proposed that threats to self-esteem best explain the costs of being helped (see also Nadler \& Fisher, 1986). Even though this experimental work is mostly on the effect of short-term help from strangers and may not necessarily generalize to real-world contexts of support in close relationships (see Wills, 1991, for a discussion of this issue), at least one study has shown self-evaluation costs of receiving aid on ego-relevant tasks from close friends (Nadler, Fisher, \& Ben Itzhak, 1983).

However received support operates, its distinctiveness from traditional measures of perceived available support is not in doubt. If perceived support is not fostered by receiving support, then how does it come about? Some researchers argue that perceived support is best understood as an individual difference variable (see Pierce, Lakey, Sarason, Sarason, \& Joseph, 1997, for a review). In this view, the feeling of being supported reflects working models of interaction based on early experiences with significant others (e.g., Bowlby, 1969).

Others have argued that perceived support is rooted in the everyday fabric of relationships, in the routine interactions that people have with their friends and partners, interactions that are not necessarily viewed as acts of support (Leatham \& Duck, 1990; Rook, 1987; Thoits, 1985). Lieberman (1986), in reviewing the finding that many people in supportive networks claim not to turn to these networks for help, has argued that such people probably do receive support but that it is delivered so smoothly that they do not notice it. Indeed, Coyne and Bolger (1990) posited that it is the absence of explicit support that may attest to the strength of a close relationship. Explicit or "visible" acts of support from a close partner may represent reparative work, potentially signaling prob- lems in the relationship. Thus, one possible explanation for the discrepancy between the effects of perceived and received support is that the most effective support from friends and partners takes place "between the lines" and either goes unnoticed or is not interpreted as support. This is what we refer to as "invisible support" (Bolger et al., 2000).

\section{When Support Visibility Matters in Dyadic Interaction}

Supportive acts can be distinguished in terms of their location in a stress and support process. In the case of dyads, Figure 1 shows a progression of stages that begins with a focal person experiencing a demanding event or activity and ends with her or him asking for help from a dyad partner. Highlighted by numbered arrows are potential points of support provision by the partner, support that if successful can prevent a progression to the next stage in the process. Although necessarily simplified, Figure 1 allows us to make some useful distinctions.

The major distinction shown in Figure 1 is between what we term anterogatory points of support provision (1-4), those that occur before the focal person has reached a stage of asking for support, and postrogatory points (5), those that occur following a request for support. Although there are exceptions, our view is that invisible support is most likely to occur and functions best in the anterogatory stages. Visible support, by contrast, is more likely to be a net benefit in postrogatory stages, but depending on the stressor and relationship context, it may also be beneficial at earlier stages.

The first point of support provision is where the dyad partner prevents the occurrence of a demanding event. If this is accomplished outside of the recipient's awareness, no appraisals of stressfulness, of personal competence, of support needs, or of coping effort will be required of the recipient. Thus, spouses with a major illness may be shielded from exposure to household and child care stressors by the behind-the-scenes efforts of their partners.

A second point of support provision is one in which a demanding event or activity occurs but the presence or actions of the dyad partner prevent recipients from appraising it as stressful. For example, if one spouse receives word of an upcoming job interview, the partner's deliberate adoption of a calm positive manner can result in the spouse appraising the interview as an opportunity rather than a threat.

A third point of support provision, and the one we examine empirically in this article, is one in which an already stressed person receives help without having to explicitly ask for it. Such
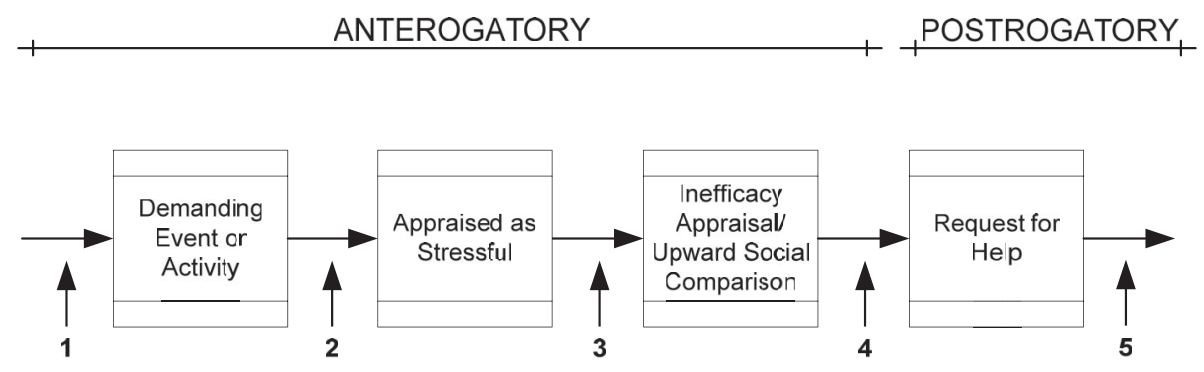

Figure 1. Hypothetical stress and support process for a dyad member, showing alternative points of support provision by the dyad partner 
acts are invisible to the recipient when they are enacted in a sufficiently subtle or indirect way that the recipient does not interpret them as support. An example might be support that is delivered under the guise of seeking rather than offering information, as in the case of an employee who aids a struggling coworker by seeking help from a supervisor on a shared task. Another example might be one in which a peer strategically evokes distress-reducing social comparisons in a student worried about an upcoming examination by drawing attention to her own lack of preparation. We suspect that skillful, indirect methods such as these are common ways that invisible support is enacted, particularly when potential supporters are peers. By contrast, visible support given at this point in a stress process involves the risk of invoking or increasing recipients' sense of incompetence and, in peer dyads, recipients' tendency to see themselves as less competent than the support provider (i.e., to make upward social comparisons on competence).

A fourth point of support provision is one in which the stressed person has made the judgment that he or she is not able to cope with the stressor but has not yet overcome any concerns about autonomy or appearing incompetent to decide to ask for help. Here we believe that for skillful support providers the balance is still in favor of providing invisible support, but depending on the type of dyadic relationship (e.g., peer vs. intimate partner), the identity relevance of the stressor, and the competence of the partner in the stressor domain, visible support may be more appropriate. Of course, if such support is given in a heavy-handed way, it may reinforce feelings of inefficacy and in peer dyads increase upward social comparison.

The final point of support provision is one in which a partner explicitly asks for help. Visible support given at this point typifies the canonical support transaction, and assuming the support matches the needs of the recipient (Cutrona \& Cole, 2000; Cutrona $\&$ Russell, 1990), it can help him or her to reappraise the situation as less threatening or to cope effectively with it.

\section{An Experimental Paradigm for Studying Support Visibility Effects in Peer Dyads}

The Bolger et al. (2000) article was unable to empirically distinguish when in a daily stress process invisible support occurred, but the presumption was that it occurred at the anterogatory stage, that is, at Points 1-4 in Figure 1. As noted above, our focus in this article is on support visibility at Point 3 in the process, where participants already appraise a situation as stressful but have not reached a sufficiently negative view of their competency that they decide to ask for help.

Central goals of the current research, therefore, were to improve on the Bolger et al. (2000) study (a) by being explicit about the content and timing of the supportive acts and (b) through experimental control to render these acts uncorrelated with the recipient's distress and other potential third variables. Also, (c) this research sought to examine mechanisms that could explain why invisible support was more effective than visible support. Was invisible support more effective because recipients were less aware of their own difficulties and distress, had a greater sense of efficacy or a reduced sense of indebtedness?

To accomplish these goals, we developed a laboratory-based stressor and support paradigm to be used with undergraduate participants. The stressor involved exposing participants to a demanding achievement-related situation, one in which they expected to give a speech on a topic personally important to them and to be evaluated by an audience of graduate students. Support visibility was manipulated by using a confederate posing as a student peer who provided help to the participant in one of several carefully scripted ways. The key experimental outcome was participants' emotional reactivity to the stressor, which was assessed by the rise in their psychological distress because of the anticipated speech.

There are major differences between the current experimental approach and the nonexperimental field study approach in which the invisible support phenomenon was originally demonstrated. Nevertheless, essential elements of the invisible support phenomenon are preserved, namely, a dyadic context in which a focal person's competence in a valued domain is challenged and a dyad partner enacts support in ways that vary in their visibility to the focal person. From a theoretical point of view, the most important difference between the two approaches is that the current approach focuses on support from an unfamiliar peer rather than from an intimate partner. People's normative expectations are that they can rely on intimate partners for support but cannot rely upon it from unfamiliar peers. We took pains, therefore, to create a situation in which the provision of support by an unfamiliar peer was a reasonable event. Also of theoretical significance is the likely role of social comparison processes when support is being offered by a peer, someone who is more likely than an intimate partner to have competencies that are similar to the person under stress.

We chose to implement the stressor using an anticipated speech paradigm because this paradigm is known to be an effective laboratory stressor among undergraduates and can be extended to incorporate support provision by a confederate peer (Pierce, Sarason, \& Sarason, 1992; Uchino \& Garvey, 1997; Winstead, Derlega, Lewis, Sanchez-Hucles, \& Clarke, 1992). Participants' investment in the speech task was increased by having them speak on a topic that they had preselected as personally important. Furthermore, we used a cover story that was likely to be both stressful and meaningful to college students: grading of their performance in a valued domain.

The specific context in which the confederate peer provided support was designed to be natural, if not expected: Support was provided immediately following the participant's usually poor delivery of a short practice speech and immediately prior to the anticipated real speech. Thus the support was intended to be a reasonable response by a peer to the participant's difficulties in coping with a personally meaningful stressor.

Support visibility was manipulated by having the confederate peer address the support content, whether practical (e.g., advice) and/or emotional (e.g., reassurance), either (a) directly to the participant such that it would be interpreted as a supportive act (visible) or (b) indirectly as a query to the experimenter such that it would be helpful to the participant but not perceived as support (invisible). The outcome variable, emotional reactivity to the stressor, was measured as a change in distress from the beginning of the study, when participants were unaware of its specific purpose, to immediately after the support manipulation and immediately prior to the anticipated speech.

In our experiments, we restricted our focus to female participants and female peer confederates. Although this limits general- 
izability, we wished in these initial experiments to avoid cross-sex interactions in which support provision could possibly be interpreted by participants as displaying romantic or sexual interest on the part of the confederate (as in the case in which Clark \& Mills, 1979, used male participants and female confederates to study desire for a communal relationship). In addition, past researchers have demonstrated that gender composition is an important moderator of the effects of support receipt (Derlega, Barbee, \& Winstead, 1994; Winstead et al., 1992). A final reason for restricting our initial experiments to women was because of the argument that women's reactions to stressors rely more on support giving and receiving, namely, the "tend and befriend" response, rather than the "fight or flight" response more characteristic of men (Taylor et al., 2000).

Study 1 used a two-groups design and compared the effects of visible and invisible practical support on distress. Study 2 compared the effects of visible and invisible emotional support on distress and included a no-support control group. Study 3 was designed to examine mediating factors that could account for differential effects of visible and invisible practical support.

\section{Study 1}

We began by focusing on visibility effects for practical support because prior experimental research had shown that such support had self-esteem costs (i.e., Fisher et al., 1982; Nadler et al., 1983). We hypothesized that when faced with the prospect of giving a stressful speech, those participants who obtained advice on public speaking indirectly and invisibly would experience less anticipatory distress than would those who obtained it directly and visibly.

\section{Method}

Participants and design. Thirty-five female participants were recruited from the New York University undergraduate participant pool. Participants were all Introduction to Psychology students who participated in studies as part of their course requirement. Participants were randomly assigned to the two conditions, which resulted in 18 being in the visible support condition and 17 in the invisible support condition. However, 4 participants later reported being suspicious about the cover story and were dropped from analyses. This resulted in a final sample of 31, with 16 in the visible support condition and 15 in the invisible support condition. The mean age of included participants was 19.3 years $(S D=2.9)$. The ethnicity breakdown was 58\% Caucasian, 16\% Hispanic, $13 \%$ Asian, 7\% African American, and 6\% other/unknown.

The experiments, including the debriefing, took approximately 20 min to complete. Studies 1 and 2 used almost identical procedures and measures. Participants were students who signed up for a purported study on teacher-student interactions entitled "Better Grades." They were greeted in the psychology department waiting area by a female experimenter and discovered that another female student in the waiting area (in reality, the confederate) would be joining them in the experiment. All confederates were casually dressed women in their early 20s. The experimenters were more formally dressed women in their late 20s. Before delivering the full cover story, the experimenter administered a baseline questionnaire to the participant and the confederate peer.

After they completed the baseline questionnaire, the experimenter told the participant and confederate that the research team was studying grading bias effects and that both of them would perform academic tasks that would be evaluated by graduate teaching assistants. One student would give a speech and the other would write an essay. The experimenter explained that the purpose of the experiment was to compare two evaluations of students' performance: One graduate assistant would see students' demographic and grade information from their baseline questionnaires and a second graduate assistant would not.

The experimenter then informed the participant and confederate peer that through random assignment the participant would be required to give a speech and her peer would be required to write an essay. Both were told that the topic for their respective tasks would be the one they had identified as personally important in the baseline questionnaire. They were also told that the experimenters were seeing students in pairs so that the student assigned to the academic essay task (the confederate) could act as a practice audience while the other student composed her speech aloud. Following these instructions, the participant was given $5 \mathrm{~min}$ to practice her speech. Without exception, participants were dismayed to hear that they had been assigned to give a speech, but all proceeded with the practice phase of the experiment. Given the brief period allotted to practice, few participants managed to produce a polished version of their speech, and almost all appeared unhappy with their practice efforts.

The support manipulation (described below) occurred after the practice period was complete. Following the support manipulation, the confederate left the room to (supposedly) write her essay. A final short questionnaire was then administered to the participant, after which she was led to believe she would give her speech. At this point, the participant underwent a suspicion check, followed immediately by the revelation that she would not, after all, have to give her speech. She was then debriefed and the experiment was concluded. Note that the experimenter moved the experiment along at a brisk pace throughout to prevent unscripted interaction between the participant and confederate.

Because the experiment induced considerable distress, participants went through extensive debriefing according to recommendations by Mills (1976) for experiments using deception and/or stress. The experimenter described the true hypotheses and explained that deception was necessary in order to induce feelings of stress in the participant and to manipulate support visibility.

Variables and measures. Both the baseline and final questionnaires were two pages long. In addition to the measures described below, the baseline questionnaire included demographic questions and the measure of topic and task importance. For the latter, the instruction read: "Here is a list of current issues or concerns. Please check one issue that is most important to you-or write in your own." Participants chose from "abortion," "homelessness," "drugs," "AIDS," or "other." The selection was then rated for personal importance on a 5-point scale $(0=$ not at all; $1=$ a little; $2=$ moderately; $3=$ quite a bit $; 4=$ extremely). It was participants' choice of topic that became the subject of their anticipated speech task. Both questionnaires also included several items whose purpose was to maintain the cover story (e.g., "People get the grades they deserve"; "Teachers tend to favor certain students").

Support provision. As noted earlier, the support manipulation occurred following the practice period and immediately before the confederate peer left the room (supposedly to write her essay). The support behaviors were designed to appear credible and norma- 
tively appropriate given the confederate's role as a fellow student participant and the excessive demands of the experimental task that led it to be stressful for virtually all participants.

The support conditions were cued as follows: When the participant completed her practice speech, the experimenter said, "It's about time for both of you to do your tasks," and directly addressing the confederate, the experimenter said "[Confederate], do you have any questions for me before we move on?" To the experimenter's query, the confederate made one of two replies, each representing a support visibility condition.

Table 1 shows the scripts for the confederate peer replies. The advice that was embedded in these replies was a common speaking tip, taken from an informal analysis of primers on public speaking (e.g., Carnegie, 1990). To reduce the possibility of bias, the experimenter remained blind to the experimental condition until as late as possible in the experiment, specifically, until after the participant had begun her practice speech. At this point, the experimenter consulted an assignment sheet that specified the condition to be implemented. The confederate peer (who was blind to the experimental hypotheses) was blind to the experimental condition until immediately prior to the support manipulation, when she was cued by a cover sheet given to her by the experimenter.

In the visible support condition the confederate peer addressed the public speaking tip directly to the participant, whereas in the invisible condition she addressed it to the experimenter in the form of a question. Confederates were extensively trained to be consistent in their delivery and to project a warm, benevolent manner. Their vocal intonation in the visible support condition reflected such a supportive attitude so as to avoid the possibility of insulting or demeaning the participant.

The manipulation check for practical support visibility was the item "My partner offered me information or advice," which was embedded in the final questionnaire as part of a 12-item checklist. The instructions accompanying the checklist were "Please check all events that occurred during the practice period. Check all that apply." The remaining checklist items were oriented to the cover story (e.g., "I pictured myself giving the actual talk while practicing"; "I learned something about myself or my topic").

Emotional reactivity: Change in distress. Distress was measured in the baseline and final questionnaire using six items from the Profile of Mood States (Lorr \& McNair, 1971). The Profile of Mood States is a well-validated measure of mood, and it has been shown to reliably detect stress-related changes within persons in a range of moods, including anxiety, depression, anger, fatigue, and vigor (Cranford et al., 2006). The six items comprised the three that loaded highest on the Anxiety and Depression subscales in validation work on college students (see Lorr \& McNair, 1971).
Participants read the following instructions: "Here is a list of feelings or experiences. Please rate how you feel right now." Each item was rated by participants on a 5-point scale with labels not at all, a little, moderately, quite a bit, and extremely.

Participants' ratings on each item were mapped onto a $0-10$ scale, on which 0 represented a rating of not at all and 10 represented a rating of extremely. A distress score was then computed by taking the mean of all six items. Thus a score of 0 represented the lowest possible rating of distress and a score of 10 represented the highest possible rating. To calculate how distressing the anticipated speech task was for participants, we used a simple change score, subtracting their baseline distress from their final distress. In this way stressor reactivity was calculated relative to each participant's own baseline. Coefficient alphas for baseline, final, and change in distress were $.74, .84$, and .75 , respectively. Although concerns have long been voiced about the typically low reliability of change scores (e.g., Cronbach \& Furby, 1970), such low reliability is not inevitable, particularly in studies in which the design is likely to produce appreciable change and the measures are sensitive to change (Cranford et al., 2006; see Taris, 2000, Chapter 4 , for a discussion of factors affecting the reliability of change scores).

\section{Results and Discussion}

Manipulation checks on experimental conditions: Task importance, task stressfulness, and practical support visibility. Recall that the experiment was designed to have participants (a) expect to give a speech on a topic that was important to them, (b) experience a rise in distress in anticipation of giving the speech to an evaluative audience, and (c) interpret a peer's behavior as either supportive (visible) or not (invisible). Below we provide evidence on our success in achieving these conditions.

Regarding task importance, participants rated the topic of their speech as "quite a bit" important to them, averaging a 3.26 out of $4(95 \%$ confidence interval $[\mathrm{CI}]=3.09,3.43$; all subsequent $\mathrm{CIs}$ refer to $95 \%$ coverage). As expected given random assignment, there was no significant difference in task importance between the two support conditions, $t(29)=0.10, p=.919$.

Clear evidence emerged that the task was perceived as stressful. Faced with the prospect of delivering a hastily prepared talk to be evaluated by two graduate students, the typical participant's distress rose from her baseline level of 2.29 units on a $0-10$ scale $(S D=1.76, C I=1.64,2.93)$ to 4.34 units immediately before she expected to deliver the talk $(S D=2.43, \mathrm{CI}=3.45,5.23)$, paired $t(30)=5.44, p<.0001$. This corresponds to a standardized effect

Table 1

Study 1 Peer Support Conditions Formed by Confederate Peer's Response to Experimenter's Question "Do You Have Any Questions for Me Before We Move on?"

\begin{tabular}{ll}
\hline Condition & Peer's response \\
\hline Visible & $\begin{array}{l}\text { Not really. But I would like to say something to [Participant] if that's all right. You know, to } \\
\text { give a good talk it's probably most important to summarize what you're going to say at the } \\
\text { beginning, and also to make a strong conclusion at the end." } \\
\text { Invisible }\end{array} \quad \begin{array}{l}\text { Yes, I've got a question about what we're supposed to be doing. I thought that for this kind } \\
\text { of thing, it's probably most important to summarize what you're going to say at the } \\
\text { beginning, and also to make a strong conclusion at the end?" }\end{array}$ \\
\hline
\end{tabular}


size (J. Cohen, 1988) of $1.04 S D$ units $^{1}\left(\mathrm{CI}_{d}=0.65,1.43\right)$. Given that Cohen recommended that effects of $0.2 S D$ units be labeled "small," .5 be labeled "medium," and .8 be labeled "large," it can be seen that even the lower bound of the CI (0.65) is in the medium-to-large range. Consistent with random assignment to condition, there were no initial distress differences between conditions, $t(29)=1.08, p=.286$.

The manipulation check for practical support visibility showed that all 15 participants in the visible support condition reported receiving support (i.e., in the final questionnaire they checked the item "My partner offered me information or advice"), whereas none of the 16 participants in the invisible support condition did so.

Effect of support visibility on change in distress. Our hypothesis was that invisible practical support would have a more ameliorative effect on distress compared with visible practical support. To test this hypothesis, we examined whether premanipulation to postmanipulation increases in distress were smaller for the invisible support condition. To decrease the error variance against which the experimental effect would be assessed (and thereby increase statistical power), we included initial level of distress as a standard experimental covariate. The hypothesis was confirmed: Participants' distress rose considerably less when support was invisible compared with when it was visible. Adjusting for initial level of distress, we found that distress rose 1.05 units $(\mathrm{CI}=0.10$, 2.00) for participants in the invisible support condition, whereas it rose 3.13 units $(\mathrm{CI}=2.15,4.12)$ for those in the visible support condition. This three-fold difference in the original units corresponds to a large effect in standard deviation units $\left(d=-1.09{ }^{2}\right.$ $\left.\mathrm{CI}_{d}=-1.81,-0.37\right), t(28)=3.10, p=.004 .^{3}$ The lower bound estimate of the effect was substantially smaller but still in the small-to-moderate range $(-0.37)$.

Although this preliminary experiment established the feasibility of manipulating support visibility in a laboratory setting and produced results consistent with the Bolger et al. (2000) nonexperimental findings, it left basic questions unanswered. Were the group differences we found attributable to beneficial effects of invisible support, deleterious effects of visible support, or both? Would the results found for practical support also apply to emotional support, the other major form of support examined in the literature?

\section{Study 2}

To address these questions, in Study 2 we included a no-support control condition, and we examined whether support visibility effects could be shown for emotional support. We hypothesized that invisible support would be beneficial compared with no support because when support is made invisible to the recipient the benefits of the support content are accrued and the costs of support awareness are avoided. By the same logic, we hypothesized that for visible support the benefits of the support content would be offset by the costs of support awareness, perhaps leaving recipients no better off than if they had not received support at all.

\section{Method}

Study 2 differed only slightly from Study 1 in terms of methodology. The same measures were used ${ }^{4}$ and, for the most part, the experimental procedure was identical. The following describes only the ways in which it deviated from Study 1.

Ninety-six female participants were recruited over two semesters at New York University as part of a course requirement for Introduction to Psychology. Five participants did not complete the experiment because they found the prospect of giving a speech too distressing. All but 1 dropped out prior to the practice period and before support was manipulated. Additionally, based on the suspicion check, 5 other participants were dropped from the study (these participants were not concentrated in any particular experimental condition). The final sample consisted of 86 participants, of whom 29 were in the visible support condition, 27 were in the invisible support condition, and 30 were in the no support condition. The mean age of included participants was 18.9 years $(S D=$ 1.0), and the ethnicity breakdown was Caucasian, 60\%, Asian, $14 \%$, Hispanic, $13 \%$, African American, 10\%, and other/unknown, $4 \%$.

Our operationalization of emotional support provision was to have the confederate peer tell the participant that she had "nothing to worry about, that she would do fine." In the visible emotional support condition this opinion was expressed directly to the participant. In the invisible emotional support condition, the confederate expressed this opinion of the participant as part of a question to the experimenter about the confederate's task. In the no support condition, the confederate did not refer either directly or indirectly to the participant. The specific wording used in each condition is shown in Table 2.

\section{Results and Discussion}

Manipulation checks on experimental conditions: Task importance, task stressfulness, and emotional support visibility. We first present data showing that the experimental conditions of task stressfulness, task importance, and support visibility versus invisibility were met. Regarding task stressfulness, averaging over the support conditions, participants' distress rose 1.60 units on a $0-10$ scale from baseline $(M=2.06, S D=1.92, \mathrm{CI}=1.65,2.48)$ to final levels, $M=3.66, S D=2.38, \mathrm{CI}=3.15,4.17)$, paired $t(85)=$ $6.65, p<.0001\left(d=0.78, \mathrm{CI}_{d}=0.54,1.01\right)$. As anticipated, initial distress did not differ across conditions, $F(2,83)=1.54$, $p=.220$

As in Study 1, the average participant rated the topic of her speech as being between "quite a bit" and "very" important to her

\footnotetext{
${ }^{1}$ In this case we used a version of Cohen's $d$ adapted for within-subjects comparisons, a version in which the standard deviation estimate combined both between- and within-subject variance (see Maxwell \& Delaney, 2004, pp. 547-550).

${ }^{2}$ As recommended by Maxwell and Delaney (2004, pp. 431-434), we used a standard deviation estimate that did not remove variance due to the covariate.

${ }^{3}$ An additional analysis without covarying initial distress produced results with almost identical mean differences, slightly larger standard errors, and slightly larger probabilities. This is to be expected: Given that random assignment resulted in initial distress being unrelated to support condition, initial distress functioned as a standard experimental covariate and increased statistical power (see Kutner, Nachtsheim, Neter, \& Li, 2005 , pp. 939-940 for a concise discussion of this issue). Note that a similar pattern was found for Study 2 and Study 3.

${ }^{4}$ In Study 2, coefficient alphas for baseline, final, and change in distress were $.84, .89$, and .83 , respectively.
} 
Table 2

Study 2 Peer Support Conditions Formed by Confederate Peer's Response to Experimenter's Question "Do You Have Any Questions for Me Before We Move on?"

\begin{tabular}{ll}
\hline Condition & \multicolumn{1}{c}{ Peer's response } \\
\hline Visible & "Not really. But I would like to say something to \\
& [Participant] if that's all right. Look, you've \\
& got nothing to worry about, you'll do fine. I'd \\
& understand if you were nervous, but I really \\
& think it's going to be okay." \\
"Yes, can you tell me more about what I'm \\
doing? I mean, [Participant] is going to do \\
fine, she's got nothing to worry about, but I \\
still don't know what I'm supposed to do." \\
"Not really. Unless you're going to tell me more \\
about what I'm supposed to do?" \\
No support
\end{tabular}

$(0-4$ scale; $M=3.3, S D=0.5)$. There were no significant differences in task importance across conditions, $F(2,83)=1.72$, $p=.14$. The manipulation check for emotional support receipt (embedded in the 12-item checklist in participants' final questionnaire) was "My partner offered me reassurance." All but 1 participant checked this item in the visible support condition (28 of 29), and all but 1 did not check it in the no-support condition ( 1 in 30). However, one quarter of participants in the invisible support condition checked it ( 7 of 27). Because we were concerned that the inclusion of these 7 participants might affect the main results, we ran all subsequent analyses twice, once with them included and once with them excluded. Because inclusion or exclusion had no effect on the findings we present the results for the complete sample.

Effect of support visibility on change in distress. As Figure 2 illustrates, distress rose least in the invisible support condition (0.87 units; $\mathrm{CI}=0.07,1.66)$, whereas it rose most in the visible support condition $(2.22$ units; $\mathrm{CI}=1.46,2.98)$. Participants in the no support condition showed an intermediate rise (1.65 units; $\mathrm{CI}=$ $0.90,2.39$ ). A one-way analysis of covariance (ANCOVA) with initial distress as a covariate was used to analyze these differences. A planned comparison of the invisible versus visible condition replicated the result found in Study $1, M_{\text {diff. }}=-1.35, d=-0.63$, $\mathrm{CI}_{d}=-1.15,-0.12, t(82)=-2.43, p<.017$, with the qualification that in this case the effect size was smaller $(-0.63$ vs. $-1.09)$ and its lower bound value was small $(-0.12)$ rather than small to moderate $(-0.37)$.

A planned comparison of the invisible and no support conditions revealed an effect in the predicted direction, with participants in the invisible condition showing lower increases in distress than those in the no support condition. Although the CI for the effect included a large benefit, it was sufficiently wide that it included zero and even a small effect in the opposite direction, $M_{\text {diff. }}=$ $-0.78, d=-0.36, \mathrm{CI}_{d}=-0.88,0.15, t(82)=-1.42, p=.159$.

For the third planned comparison, visible versus no support, recall that we predicted a null or possibly deleterious effect. Our results were consistent with this prediction, but again the confidence interval was large, ranging from a large deleterious effect to a small beneficial effect, $M_{\text {diff. }}=0.57, d=0.27, \mathrm{CI}_{d}=-0.23$, $0.76, t(82)=1.07, p=.287$.

The goals of this experiment were, first, to replicate the results of Study 1 using emotional rather than practical support and, second, to assess whether this difference, if found, was due to a beneficial effect of invisible support, a deleterious effect of visible support, or both. As shown above, the first goal was met in that stressor reactivity was significantly greater for visible than invisible support.

The results for the second goal were less clear cut. Although the observed mean differences indicated a beneficial effect of invisible support, the effect size was small to medium, and it was not possible to rule out a null or even slightly deleterious effect. For visible support, the CIs were also wide, ranging from a large deleterious effect to a null or slightly beneficial effect. Note, however, that the range of values not covered by the CIs still permits us to draw interesting and informative conclusions about the visibility of enacted support: Visible support, the canonical form studied in prior theory and research, has at best a small benefit compared with no support, whereas invisible support is likely to have a beneficial effect and has at worst a small negative effect.

\section{Study 3}

In the third and final study using the peer support paradigm, we moved beyond demonstrating the existence of support visibility effects to investigating underlying explanatory mechanisms. Given the nature of the paradigm and the results of the prior studies, we reasoned that four underlying factors needed to be distinguished. These were (a) presence or absence of support content provided by the peer (in Study 3 we returned to the content examined in Study 1 , i.e., advice), (b) its visibility to the recipient, (c) whether it communicated inefficacy in the recipient, and (d) whether it communicated inefficacy in the peer support provider. By considering these factors within a single research design, the following questions could be addressed.

First, there was the question of whether visible support was relatively detrimental because it necessarily communicated a feeling of inefficacy to the recipient and thereby offset any benefit of the support content. An opponent process such as this had been a working explanatory hypothesis since the original findings of Bolger et al. (2000) and the broader set of analyses of Shrout et al. (2006). We viewed this communication of inefficacy as an unavoidable feature of visible support interactions. This hypothesis rested on prior theoretical work that emphasized how the self is

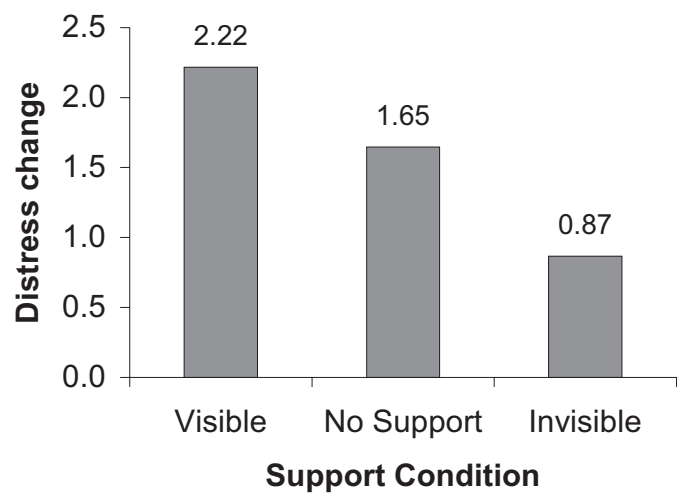

Figure 2. Study 2: Effects of peer support visibility conditions on distress change $(0-10$ scale). The standard error for each mean is approximately .39 units. 
formed and maintained by the reflected appraisals of others (Cooley, 1902/1983; Stryker \& Statham, 1985), by prior experimental work showing that help in ego-relevant domains could have self-esteem costs (e.g., Fisher et al., 1982), and more generally, by prior work showing that the negative effects of support are mediated by self-relevant judgments such as competence and efficacy (Newsom, 1999). We investigated this idea by creating a modified visible support condition, one that did not involve the communication of inefficacy.

Second, there was the question of whether the invisible support condition was relatively beneficial because its content was communicated indirectly or because the peer highlighted her own sense of inefficacy and thereby normalized the participant's sense of being inefficacious. We noted in the introduction to the article that it was possible that skillful peer supporters used this strategy to reduce the recipient's distress, and that it was plausible that the effect might operate through reducing the recipient's use of upward social comparison to the peer. Although the link between social support and social comparison is a relatively neglected one (but see Buunk \& Hoorens, 1992; Taylor, Buunk, \& Aspinwall, 1990), it seemed to us to be very relevant for this type of indirect or invisible peer support. Our working hypothesis was that in the context of the speech stressor, upward comparison to an apparently more poised and confident peer would lead to increases in distress. However, we note that the use of upward comparison is not always associated with increased distress, as in the case in which participants have the goal of learning from the comparison person (R. L. Collins, 1996).

A third issue was whether the actual content of the support was important in reducing distress. In the prior two experiments, the support content (advice, reassurance) had been confounded with visibility, recipient inefficacy, and provider inefficacy. In the new design, these factors were unconfounded. A final and related issue was whether the visibility per se of the support would be important independent of other factors. Again, the new design allowed us to disentangle support visibility from support content, provider inefficacy, and recipient inefficacy.

\section{Incomplete Factorial Design of Experiment 3}

Table 3 shows the particular combinations of the four factors we used in Study 3. If all possible combinations of factors had been included, the design would have involved 16 cells and a prohibitive number of participants. However, not all of the cells were of theoretical interest or were even logically sensible. As we detail below, we implemented an incomplete factorial design, giving priority to contrasts that "peeled away" components of what we regarded as standard visible and invisible support conditions. Our inferences are necessarily conditional on the included conditions. We first explain the rationale for the included cells and then consider the excluded ones.

The first condition in Table 3, Visible A, is what can be viewed as a standard visible support interaction in a peer context. It represents specific combinations of the four factors introduced earlier: (a) the presence of support in the form of advice on public speaking, (b) addressed directly to the recipient and presumably visible to her, (c) the communication that the recipient needed help and/or was inefficacious, and (d) the implication that the peer provider was not. Thus, in response to the experimenter's request for questions or comments, the confederate peer replied by noting that the recipient was in need of help and directed the advice on public speaking to the recipient. Also, given its context-the experimenter's query whether the peer had any questions for her-the peer's response implied that she herself was not in need of help with her writing task. Visible A was similar to the visible conditions used in the previous two experiments, with the excep-

Table 3

Study 3 Peer Support Conditions Formed by Confederate Peer's Responses to Experimenter's Question "Do You Have Any Comments for [Participant] or Any Questions for Me Before We Move on?"

\begin{tabular}{|c|c|c|c|c|c|c|c|c|c|c|c|}
\hline \multirow[b]{2}{*}{ Condition } & \multirow{2}{*}{$\begin{array}{c}\text { Practical } \\
\text { support }\end{array}$} & \multirow[b]{2}{*}{ Visibility } & \multirow{2}{*}{$\begin{array}{l}\text { Recipient } \\
\text { inefficacy }\end{array}$} & \multirow{2}{*}{$\begin{array}{c}\text { Peer } \\
\text { inefficacy }\end{array}$} & \multicolumn{6}{|c|}{ Contrast } & \multirow[b]{2}{*}{ Peer's response } \\
\hline & & & & & 1 & 2 & 3 & 4 & 5 & 6 & \\
\hline Visible A & Yes & Yes & Yes & No & $\bullet$ & $\bullet$ & & & & & $\begin{array}{l}\text { "Well, I can tell that you could use some help. I think } \\
\text { it's best to summarize what you're going to say at } \\
\text { the beginning of a speech and to end with a } \\
\text { definite conclusion." }\end{array}$ \\
\hline Visible B & Yes & Yes & No & No & & $\bullet$ & & & $\bullet$ & & $\begin{array}{l}\text { "Well, I don't think that you need any help. But, if I } \\
\text { had to say something, I've heard that it's best to } \\
\text { summarize what you're going to say at the } \\
\text { beginning of a speech and to end with a definite } \\
\text { conclusion." }\end{array}$ \\
\hline Invisible $\mathrm{A}$ & Yes & No & No & Yes & & & $\bullet$ & $\bullet$ & & & $\begin{array}{l}\text { "Well, I don't think she needs any help, but I could } \\
\text { use some help. Should I structure my essay in a } \\
\text { certain way? Like to summarize what I'm going to } \\
\text { say at the beginning, and to end with a definite } \\
\text { conclusion?" }\end{array}$ \\
\hline Invisible B & Yes & No & No & No & & & & $\bullet$ & $\bullet$ & $\bullet$ & $\begin{array}{l}\text { "Well, I don't think that she needs any help, and I } \\
\text { don't either. I'll just summarize what I'm going to } \\
\text { say at the beginning of my essay and end with a } \\
\text { definite conclusion." }\end{array}$ \\
\hline No support & No & & & & - & & - & & & $\bullet$ & "No, not really." \\
\hline
\end{tabular}

Note. The six planned contrasts are indicated by vertical pairs of bullets in the numbered columns: $1=$ visible support, $2=$ recipient inefficacy, $3=$ invisible support, $4=$ peer inefficacy, $5=$ pure visibility, $6=$ pure content. 
tion that the peer now explicitly noted that the recipient needed help. The precise script for this condition is displayed on the right-hand side of Table 3. A planned contrast of this condition with the no support condition (Contrast 1: Visible Support), allowed us to obtain a benchmark estimate of its effect, one that could be later compared with conditions in which putative component factors were manipulated.

Specifically, the next condition in Table 3, Visible B, differed from Visible A only by having the peer explicitly say that the recipient did not need help. The script used for Visible $B$ is also displayed in Table 3. Thus a contrast of the Visible A and B conditions (Contrast 2: Recipient Inefficacy) could assess whether removing the inefficacy communication had any effect on stressor reactivity.

The next condition, Invisible A, was what can be considered a standard invisible condition. It again represented specific combinations of the four factors introduced earlier: (a) support in the form of public speaking advice, (b) addressed indirectly to the recipient and intended to be invisible, (c) the communication that the recipient was not in need and/or inefficacious, and (d) the communication that the peer was. Thus, in response to the experimenter's question, the peer stated that the recipient was not in difficulty but that she herself was and communicated the support content as a question to the experimenter. This condition closely approximated the invisible condition used in Study 2, and we expected it to reduce emotional reactivity when contrasted with the no support condition (Contrast 3: Invisible Support).

The Invisible B condition was designed to be formally identical to Invisible A, with the exception that the peer said that she was not in need. Thus a contrast of Invisible A and Invisible B was designed to assess how important the communication that the peer felt inefficacious was in producing the benefits of invisible support (Contrast 4: Peer Inefficacy).

Thus far, we have discussed four planned contrasts. A fifth contrast was also planned, one comparing Visible B and Invisible $\mathrm{B}$, as these were formally equivalent except for visibility and directness (Contrast 5: Pure Visibility). Specifically, in both cases the interaction communicated that neither the provider nor the recipient was in difficulty, but in the visible case the support content was directed to the participant.

The final planned contrast was designed to assess the importance of the supportive content (Contrast 6: Pure Content). In this case the Invisible B condition was contrasted with the no support condition. In terms of the factorial design these were similar in terms of recipient inefficacy, peer inefficacy (both were low), and directness (both were indirect), but differed in content.

It is important to point out that as a result of the pattern of incompleteness in the design, these latter two contrasts were less theoretically informative than the first four. Specifically, the Pure Visibility and the Pure Content contrasts could only be assessed when both recipient and peer inefficacy were low. This limitation reflected our placing greater weight on assessing the role of inefficacy communication as explanatory variables for the effects found in the earlier studies.

We now turn to the omitted cells in the design. First, in a completely crossed design there would have been eight no support cells rather than one. We excluded four of the eight because when no support is provided it makes no sense to talk of the directness and/or indirectness of its delivery. We eliminated three more because we did not see the value of creating conditions in which no support content was provided but provider and/or recipient inefficacy was communicated. The final four missing cells represent particular combinations of visibility, provider inefficacy, and recipient inefficacy. Of these only two made theoretical sense: Both provider and recipient were in need, and the support content was either visible or invisible. We argue in the Discussion section that the theoretical yield of these cells was not sufficiently great to justify the additional design complexity.

\section{Assessing Mediating Processes}

Theory testing invariably involves the assessment of mediating processes (Brewer, 2000; Cook \& Groom, 2004; Smith, 2000). Once an experimental effect has been demonstrated, there are at least three main ways in which mediation can be assessed. The first is to conduct studies (a) that show that the experimental manipulation affects the mediator and (b) in which independently manipulating the mediator affects the dependent variable (Cook \& Groom, 2004). The second is to use experimental control to hold the putative mediator constant and, by doing so, block the experimental effect (Brewer, 2000). The third is to use the statistical modeling technique of mediational analysis (Baron \& Kenny, 1986; Hoyle \& Robinson, 2004; Kenny, Kashy, \& Bolger, 1998; Shrout \& Bolger, 2002). In principle, the latter two approaches can be used in the same study, and we used this strategy to investigate potential mediators of support visibility or invisibility effects. We reasoned that evidence of mediation that emerged in both approaches would be particularly compelling. ${ }^{5}$

The planned contrasts described earlier focus on experimental control of putative mediators, but we also measured relevant mediators to assess whether the experimental conditions differed in predicted ways on the mediators and whether these mediators, in turn, explained differences in recipient distress. We included measures of mediators that would be expected to vary as a function of the experimental manipulations, namely, the participant's reflected appraisals of their inefficacy (a likely mediator of the Visible Support contrast, given the communication of inefficacy inherent in the standard visible support condition) and the participant's reduced tendency to use upward social comparison to her peer (a likely mediator of the Invisible Support contrast, given that the peer's communication of her inefficacy should reduce the participant's sense of being in a worse situation than her peer).

\section{Method}

Participants and design. One hundred sixty-seven female participants were recruited over two semesters at New York University as part of a course requirement for Introductory Psychology. Participants were each randomly assigned to one of the five support conditions. Five participants (3\%) dropped out prior to the support manipulation because of stress. Twelve participants $(7 \%)$ were dropped from the analyses because of suspicion. These suspicious participants were not concentrated in any one condition. The mean age of the remaining 150 participants was 20.27 years $(S D=1.69)$, and the ethnicity breakdown was as follows: Caucasian (53\%), African American (7\%), Hispanic (11\%), East Asian

\footnotetext{
${ }^{5}$ See Spencer, Zanna, and Fong's (2005) recent article on conditions under which choosing one approach is preferable to the others.
} 
(13\%), other Asian (5\%), American Indian (1\%), other (11\%). The basic procedure was largely similar to that used in the previous two experiments. Below we give details on only the novel aspects of the current experiment.

Support provision. In this experiment the support provided was practical, namely the advice of "summarizing what you are going to say and end with a strong conclusion." As in earlier experiments, the support manipulation occurred following the practice period, just before the confederate left the room. To justify the inclusion of several questionnaire items about the confederate (to be used as mediators), the experimenter created a minimal expectation that support might be offered. During her explication of the cover story, she told the confederate, "After the practice period you'll get a chance to respond if you want to. But then you'll need to do your own task, okay?"

The support conditions were cued as follows: Upon completion of the practice period, the experimenter said, "It's about time for both of you to do your tasks.... [Confederate], do you have any comments for [participant] or any questions for me before we move on?" To the experimenter's query, the confederate made one of five replies; these responses were the support manipulation. See Table 3 for the confederate's script for each of the five support conditions. Note that each condition contained 30 participants.

As in the previous experiments, the manipulation check for support visibility was included in the final questionnaire, embedded in this case in an 8-item checklist of experiences during the practice period. In addition, the final questionnaire included a more general evaluation of how helpful and well-intentioned the provider appeared to the recipient. The measure, partner supportiveness, was composed of a mean of 3 items: "concerned," "helpful," "supportive" $(\alpha=.85)$. The items were included in a ten-item list of adjectives describing the student partner. The instruction read: "Here is a list of words describing your student partner. Please rate how well these words describe him or her." The five response categories were "not at all," "a little, "moderately," "quite a bit," "extremely." To facilitate interpretation of results, particularly for the mediational analyses, we rescaled this and all other rating scales to a $0-10$ interval, on which the lowest ordinal category was coded 0 and the highest was coded 10 .

Performance expectation. Because in prior experiments we had noted considerable between-persons variability in distress among participants when they learned that they were to give a speech, we included performance expectation as a control variable in analyses (see below). It was measured using a mean of two items, each rated on a 5-point scale that the participants completed prior to their practice talk. Under the instruction "Please rate your agreement right now with the following statements about your upcoming talk," the items were "I expect I will give a good talk" and "I feel pretty confident about my talk." The response categories were strongly disagree, disagree, neutral, agree, and strongly agree. The alpha for the measure was .90 .

Length of practice speech. This was measured to the nearest minute. Scores ranged from 1 to $5 \mathrm{~min}, M=3.5 \mathrm{~min}(S D=1.2$ min). This was also used as a control variable (see below).

Emotional reactivity: Change in distress. Distress was measured in the baseline and the final questionnaires and was calculated using a mean of nine items from the Profile of Mood States. These were three each from the Anxiety, Depression, and Anger subscales. The five response categories ranged from not at all to extremely. The instruction was "Here is a list of feelings or experiences. Please rate how you feel right now." The dependent variable, distress, was a simple change score from baseline to final (baseline $\alpha=.88$; final $\alpha=.90 ; \alpha_{\text {change }}=.81$ ). ${ }^{6}$

Reflected appraisal of inefficacy. A mean of two items in the final questionnaire, rated on a 5-point scale, addressed how much participants felt that the partner saw them as having a problem $(\alpha=.86)$. These were included in a list of items with the following instruction: "Some people prefer to work alone, others prefer to work in pairs or groups. Please rate your agreement with the following statements about composing your talk with a partner." The two reflected appraisal items were "My partner seemed to think I was doing fine" (reversed) and "My partner seemed to think I was having a hard time." The response categories were strongly disagree, disagree, neutral, agree, strongly agree.

Upward social comparison. Participants' use of upward social comparisons to their confederate partner was measured using the mean of two items in the final questionnaire $(\alpha=.67)$. The instructions read: "When preparing with others, feelings about a friend or partner may affect performance. Please rate how you felt with your student partner during the practice period." The items were "less knowledgeable than him/her" and "more nervous than him/her." The five response categories were not at all, a little, moderately, quite a bit, and extremely.

\section{Results and Discussion}

Here we present three sets of analyses. First, we examine whether the basic experimental conditions of task importance, task stressfulness, and support visibility were established. Next we examine how the five support conditions are related to participant reactivity to the anticipated speech task, including planned contrasts of particular conditions. Finally, we examine hypothesized mediators of the planned contrast effects.

Manipulation checks on experimental conditions: Task importance, task stressfulness, and support visibility. Averaging across the support conditions, we found that distress rose 0.92 points on a $0-10$ scale from the baseline $(M=1.77, S D=1.70)$ to the final assessment $(M=2.69, S D=2.06)$, paired $t(149)=6.35, p<$ $.0001, d=0.53, \mathrm{CI}_{d}=0.37,0.72$. Given that participants were randomly assigned to conditions, we did not expect to find differences in baseline distress among the five conditions. The data confirmed our expectation, $F(4,145)=0.92, p=.452$.

Participants rated the speech topic as personally important. The average score for task importance was 7.4 on a $0-10$ scale $(S D=$ 2.1), corresponding to a verbal label of "quite a bit important." Again there was no significant difference in task importance among the five support conditions, $F(4,145)=1.01, p=.40$.

Table 4 presents the results of the manipulation check for support visibility by condition. Overall, support receipt was endorsed as expected. Receipt was rarely reported in both invisible support conditions, never reported in the no support condition, and almost always reported in the Visible A condition. Six of the participants in the Visible B condition (20\%), however, did not report receiving support. Because removing participants whose responses were inconsistent with their condition did not alter any of the results, we used the full sample in reported analyses.

\footnotetext{
${ }^{6}$ Note that main effects of support visibility on distress were similar when the separate subscales (e.g., Anxiety) were each tested as the dependent variable.
} 
Table 4

Study 3 Manipulation Checks for Support Visibility and Perceived Supportiveness

\begin{tabular}{|c|c|c|c|c|c|}
\hline Support & Visible A & Visible B & No support & Invisible B & Invisible A \\
\hline Yes, $n^{\text {a }}$ & 29 & 24 & 0 & 3 & 1 \\
\hline No, $n$ & 1 & 6 & 30 & 27 & 29 \\
\hline Total & 30 & 30 & 30 & 30 & 30 \\
\hline \multicolumn{6}{|l|}{ Supportiveness $^{\mathrm{b}}$} \\
\hline$M($ Range $=0-10)$ & 4.6 & 5.7 & 1.7 & 2.5 & 2.7 \\
\hline
\end{tabular}

The results for the overall evaluation of partner supportiveness, shown in Table 4, were consistent with those for the manipulation check of supportive behavior. Participants in the visible support conditions rated the confederate as being "moderately" supportive $(M=5.2, \mathrm{CI}=4.6,5.7)$, whereas those in the invisible support conditions rated her as being "a little" supportive $(M=2.6, \mathrm{CI}=$ $2.1,3.1)$. Those in the no support condition gave ratings midway between "not at all" and "a little" $(M=1.7, \mathrm{CI}=0.9,2.4)$. Specific contrasts indicated that the two visible support conditions were significantly more supportive than the two invisible support conditions $\left(M_{\text {diff. }}=2.6, S E=0.4\right), t(145)=6.74, p<.0001$, and the no support condition $\left(M_{\text {diff. }}=3.5, S E=0.5\right), t(145)=7.42$, $p<.0001$. The positive difference between the invisible conditions and the no support condition was relatively small, but it also had a relatively wide CI, $\left(M_{\text {diff. }}=0.9, S E=0.5, \mathrm{CI}=-0.03\right.$, $1.8), t(145)=1.92, p=.057$. Thus, at one extreme it is possible that the conditions did not differ at all, and at the other extreme it is possible that the invisible conditions were rated almost 2 units more supportive than the no support condition.

Effects of support conditions on reactivity to stress. A oneway ANCOVA with planned contrasts was used to analyze the differences in emotional reactivity to the stressor. We included three covariates, (a) initial distress, (b) speech performance expectation, and (c) length of practice speech. Speech performance expectation and length of practice speech were new measures included in Study 3. Poorer performance expectations and longer practice speeches were associated with increased distress. Because none of the covariates differed across the five conditions and all of them were related to change in distress, they functioned as classic experimental covariates and increased statistical power. As expected, participants in the five conditions differed significantly in the extent to which their distress levels increased from the baseline to the final questionnaire, $F(4,142)=6.65, p<.001$. Figure 3 shows a bar chart of the adjusted cell means. Figure 3 also includes a visual display of the planned contrasts already detailed in Table 3.

Contrast 1: Visible support (Visible A vs. no support): Does receiving visible support have a deleterious effect on recipient distress compared with receiving no support? The results essentially replicate the effect found in Study 2. As Figure 3 shows, the rise in distress for those in the Visible A condition was 1.09 units greater than the equivalent for the no support condition $(\mathrm{CI}=0.43$, $1.75), t(142)=3.28, p<.001\left(d=0.66, \mathrm{CI}_{d}=0.26,1.05\right)$.

Contrast 2: Recipient inefficacy (Visible B vs. Visible A): Can the deleterious effect of visible support be reduced by removing the communication of recipient inefficacy? Recall from Table 3 that Visible B and Visible A differ only in the communication that the participant is in difficulty and needs help. As hypothesized, Visible
$\mathrm{B}$, in which recipients are explicitly told that they are not in difficulty, is less distressing than Visible $\mathrm{A}\left(M_{\text {diff. }}=-0.99, \mathrm{CI}=\right.$ $-1.65,-0.33), t(142)=2.95, p=.004, d=-0.60, \mathrm{CI}_{d}=$ $-0.99,-0.20$. However, the resulting mean for Visible $\mathrm{B}(0.88)$ is approximately the same as that for the no support condition (0.77). Thus, although we succeeded in creating a visible support condition that does not have a net upsetting effect, our removal of the communication that the recipient is in difficulty did not uncover an underlying positive effect of the support content (that is, the advice on public speaking).

Contrast 3: Invisible support (Invisible A vs. no support): Does receiving invisible support have a beneficial effect on recipient distress compared with not receiving support? Figure 3 shows that participants in the Invisible A showed a negligible increase in distress $(M=0.17, \mathrm{CI}=-0.30,0.63)$, whereas those in the no support condition showed a larger and significant increase $(M=$ $0.77, \mathrm{CI}=0.31,1.23)$. A planned comparison of these means, however, failed to reach significance at the .05 level $\left(M_{\mathrm{diff}}=\right.$ $-0.61, \mathrm{CI}=-1.26,0.05), t(142)=1.83, p=.069, d=-0.37$, $\mathrm{CI}_{d}=-0.76,0.03$. The $95 \% \mathrm{CI}$ reveals that the population effect size could range from -0.76 , a large beneficial effect, to .03 , a null effect. Although we cannot rule out a null effect, the CI is in large measure consistent with the idea that invisible support reduces stressor reactivity.

Contrast 4: Peer inefficacy (Invisible B vs. Invisible A): Can removing providers' communication of their inefficacy undo the beneficial effect of invisible support? The scripts for the support conditions in Table 3 show that Invisible B and Invisible A differ in whether the peer communicated that she was in difficulty or not; the results in Figure 3 show that Invisible B is significantly more distressing than Invisible A $\left(0.91\right.$ v. $0.17, M_{\text {diff }}=0.75, \mathrm{CI}=0.09$, 1.40), $t(142)=2.25, p=.026, d=0.45, \mathrm{CI}_{d}=0.05,0.84$. The mean for Invisible B is approximately the same as that for the no support condition. Thus, removing the communication that providers are in difficulty completely undoes the benefits of the invisible support condition. One might have expected to see remaining a net positive effect of the support content communicated in the Invisible B condition. We return to this issue below.

Contrast 5: Pure visibility (Invisible B vs. Visible B): In conditions in which the provider communicates that neither she nor the recipient are in difficulty, is support visibility per se important? A contrast of Visible B and Invisible B shows essentially no difference $\left(0.88\right.$ vs. $\left.0.91, M_{\text {diff. }}=-0.04, \mathrm{CI}=-0.62,0.69\right)$, $t(142)=0.11, p=.915, d=-0.02, \mathrm{CI}_{d}=-0.42,0.37$, suggesting that if recipient and peer inefficacy is low, the visibility of the support content does not matter for recipient distress. Unfortunately, because of the highly conditional nature of this contrast, 


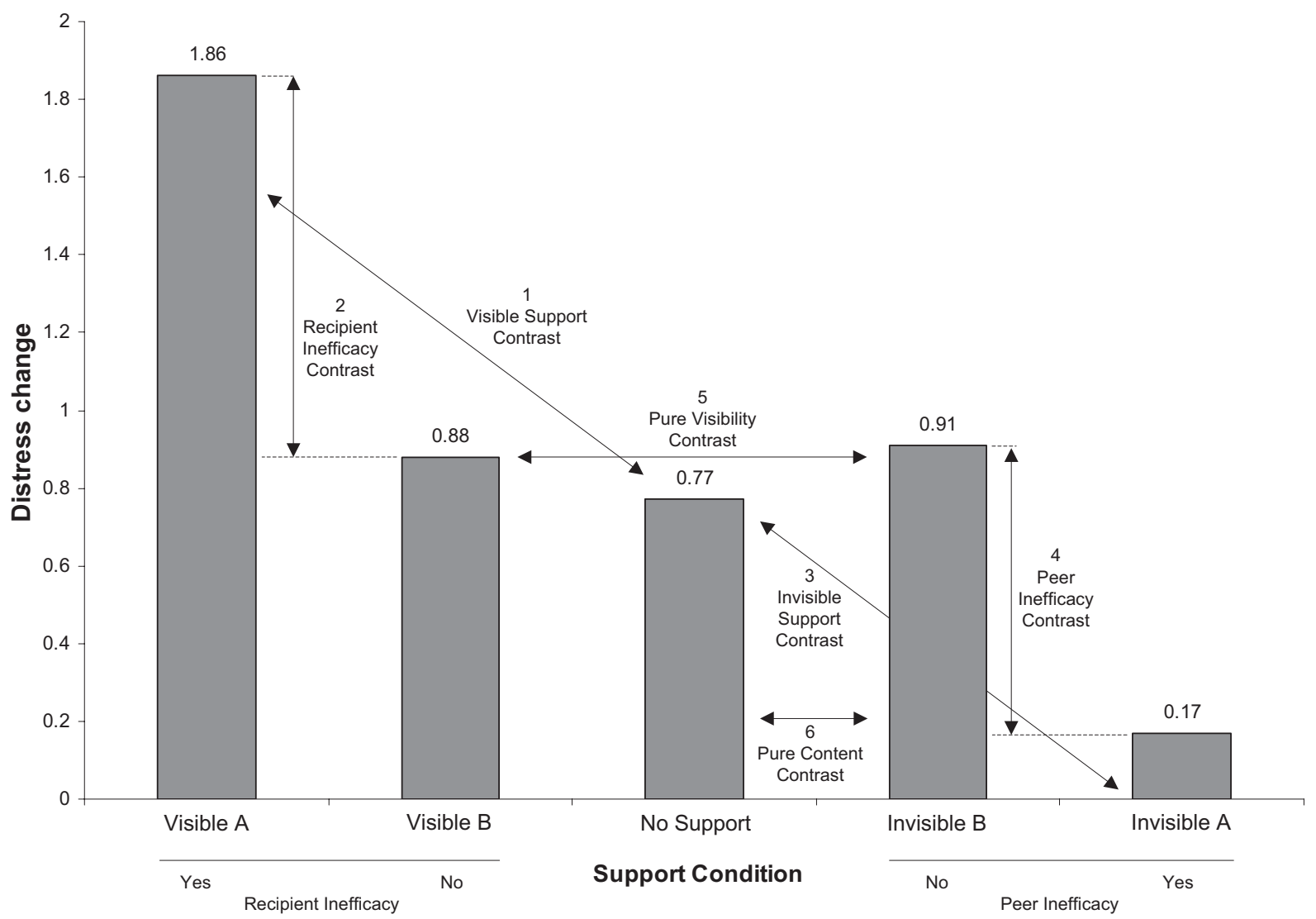

Figure 3. Study 3: Effects of peer support visibility conditions on distress change ( $0-10$ scale). The standard error for each mean is approximately .23 units.

it is more difficult to interpret than the previous ones. It may be that visibility per se has no effect in general, but it may also be that visibility has no effect when recipient and peer inefficacies are low.

Contrast 6: Pure content (Invisible B vs. no support): In conditions in which the provider communicates that neither she nor the recipient are in difficulty, is support content per se important? A contrast of Visible B and no support again reveals no difference between the conditions ( 0.91 vs. $0.77, M_{\text {diff. }}=0.14, \mathrm{CI}=-0.52$, $0.80), t(142)=0.42, p=.673, d=0.08, \mathrm{CI}_{d}=-0.31,0.48$, suggesting that in cases for which provider and recipient inefficacy is low, the content of the support, namely, the advice on public speaking does not matter for recipient distress. Although it may be that the speaking advice is of no value to the recipient, the same limitation applies to this result as to the previous one.

In summary, based on the planned contrasts of the experimental conditions, it appears that removing the communication of recipient inefficacy undoes the deleterious effect of the original visible support condition and that removing the communication of provider inefficacy undoes the beneficial effect of the original invisible support condition. As we see, however, these interpretations do not completely agree with the mediational analyses that will follow.

Mediational analyses. We included in Study 3 measures of reflected appraisals of inefficacy and upward social comparison so that we could use a mediational analysis (Baron \& Kenny, 1986; Kenny et al., 1998) to see whether these variables helped explain the pattern of results revealed by the planned contrasts. Note that we did not conduct this analysis for the final two contrasts (Invisible B vs. Visible B; Invisible B vs. no support), as these revealed negligible mean differences.

To understand the way the mediational analyses were conducted, it is useful to think of the one-way ANCOVA reported above as a regression analysis. It is now well understood that an appropriately specified regression model can produce parameter estimates identical to those of a standard analysis of variance ( $\mathrm{J}$. Cohen, Cohen, West, \& Aiken, 2003). Thus one can use regression to implement a particular analysis of variance or ANCOVA contrast by using appropriately coded dummy variables and control covariates. For example, to implement the visible support contrast, we constructed a set of four dummy variables. First we constructed a Visible A dummy variable, in which participants in the Visible A condition received a score of 1 and all other participants received a score of 0 . We constructed similarly coded dummies for the Visible B, Invisible A, and Invisible B conditions, and we left the no support condition as an omitted category. In a regression model with this set of dummy variables (and the control variables discussed earlier), the regression coefficient for the Visible A dummy variable was an adjusted mean difference in distress change between it and the no support category. Once the original ANCOVA analysis was implemented using a regression approach, we then included appropriate mediators in the model and proceeded with a standard mediation analysis. 
Thus, Step 1 of the analysis involved estimating a regression model with the four dummy variables and the three covariates as independent variables and change in distress as the dependent variable; this reproduced the estimates for a particular contrast, that is, Visible A versus no support. Step 2 involved two regressions, one for each mediator, in which the dummy variables and covariates were again treated as a set of independent variables and each mediator was treated as a dependent variable. The third and final step involved including the mediators as additional independent variables in the model estimated in Step 1 (see Kenny et al., 1998, for a worked example involving multiple mediators).

Visible support contrast. As already noted, participants in the Visible A condition showed a 1.09 units greater increase in distress than participants in the no support condition. In the language of mediation analysis, this is the total effect to be explained (obtained in Step 1 of a mediation analysis), and it is listed in the first row, final column of Table 5. To what extent can this difference be explained by the mediating variables, particularly reflected appraisal of inefficacy? The second column of Table 5, labeled "Path to" shows the link between the Visible A versus no support contrast and reflected appraisal of inefficacy (Step 2 of the mediation analysis). It shows that participants in the Visible A condition were approximately 2 units higher in inefficacy appraisal (on a $0-10$ scale $)$ than those in the no support condition $\left(M_{\text {diff. }}=2.15\right.$, $S E=0.43), t(142)=4.91, p=.000, \mathrm{CI}=1.28,3.01$.

The third column in Table 5, labeled "Path from," shows results from Step 3 of the mediation analysis, the step that traces the link between reflected appraisal of inefficacy and change in distress, while holding the other mediator (upward social comparison) and the Step 1 IVs constant. It shows that participants who were 1 unit higher in inefficacy appraisal were on average 0.23 units higher in increases in distress $(S E=0.06), t(140)=3.82, p=.0002, \mathrm{CI}=$ $0.11,0.34$.

The product of these two links, $2.14 \times 0.23=0.49$ (shown in the fourth column, labeled "Mediated"), is the portion of the original Visible A versus no support contrast that is mediated by inefficacy appraisal. Using the Shrout and Bolger (2002) bootstrap approach to assessing sampling variability of mediated effects, we found this effect to be statistically significant and to have a lower bound $\mathrm{CI}$ that was considerably greater than zero $\left(\mathrm{CI}_{b}=0.19\right.$, $0.91, p=.003$, where $\mathrm{CI}_{b}$ refers to the bootstrap $\mathrm{CI}$ ). Note that because the bootstrap approach did not assume a particular sampling distribution for the indirect effect, there was no conventional distribution-based test statistic (e.g., $t, z$ ) to report. We used this bootstrap approach because it provides a more accurate and statistically powerful test of the significance of a mediated effect than the usual Sobel test (Sobel, 1982, 1986). Details on the bootstrap approach together with worked examples can be found in Shrout and Bolger (2002).

We can see from the equivalent columns for upward social comparison that it was not an appreciable mediator of the contrast. Although engaging in upward social comparison was associated with increased distress irrespective of condition (coefficient $=$ $0.31, S E=0.09), t(140)=3.59, p=.0005, \mathrm{CI}=0.14,0.48$, participants in the two conditions did not differ substantially in their use of upward social comparison. The estimate of the mediated effect is 0.11 and is not statistically significant $\left(\mathrm{CI}_{b}=-0.05\right.$, $0.37, p=.144$ ).

Taken together, inefficacy appraisal and upward social comparison accounted for 0.60 units, or just over half of the contrast mean
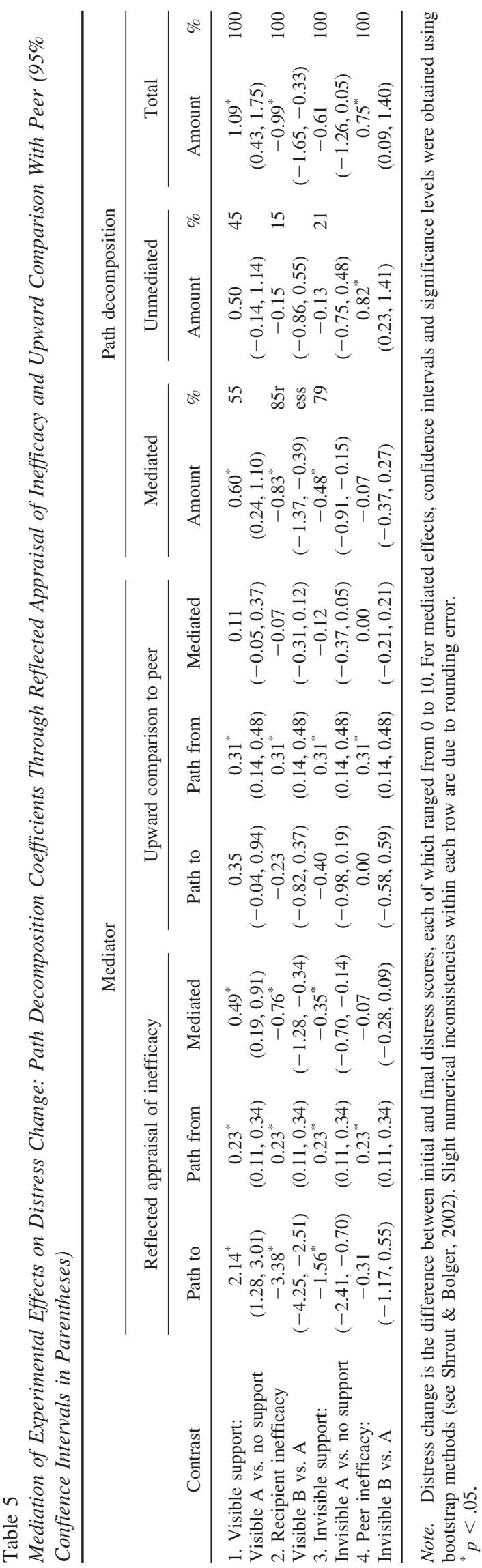
difference of 1.09 units, with inefficacy appraisal alone accounting for $45 \%$ of the mean difference. The remaining portion of the contrast, 0.50 units, is shown under the label "Unmediated." This estimate was obtained in Step 3 of the mediational analysis.

Recipient inefficacy contrast. We have already shown that compared with the no support condition, the standard Visible A condition was emotionally detrimental and that almost half of this difference was attributable to recipients reporting greater reflected appraisals of inefficacy. Given that the Visible B condition, in which recipient inefficacy was not communicated, resulted in a relative reduction in distress compared with Visible A $(-0.99$ units), can this relative reduction be accounted for by the recipient reporting less inefficacy appraisal? The answer is a very clear yes. Recipients in the Visible B condition reported an average of 3.38 units less inefficacy appraisal than recipients in the Visible A condition. Given that for each additional unit of inefficacy appraisal, distress change increased by 0.23 units, this accounts for a distress difference of $-3.38 \times 0.23=-0.76$ units $\left(\mathrm{CI}_{b}=-1.28\right.$, $-0.34, p=.004$ ), which is approximately $75 \%$ of the total difference between the conditions. Note that upward social comparison appears to play no role in accounting for this contrast.

Invisible support contrast. The mediational analysis of this contrast revealed that although we had hypothesized that reduced upward comparison would help account for the benefits of invisible support, this was not the case. As Table 5 shows, participants in the Invisible A condition were less likely to engage in upward social comparison than those in the no support condition, but the mean difference was relatively small and not significant (coefficient $=-.40), t(142)=1.34, p=.182, \mathrm{CI}=-0.98,0.19$. This failure to find mediation by upward social comparison is somewhat inconsistent with the experimental results shown earlier.

Instead, reflected appraisal of inefficacy emerged as a key mediator. Participants in the Invisible A condition were 1.56 units less likely to engage in inefficacy appraisal than those in the no support condition, $t(142)=3.59, p=.0005, \mathrm{CI}=-2.41,-0.70$, and given that a 1-unit lower inefficacy appraisal was associated with 0.23 units lower distress, the indirect effect is $-1.56 \times$ $0.23=-.35$ distress units $\left(\mathrm{CI}_{b}=-0.70,-0.14, p=.002\right)$.

Peer inefficacy contrast. In this final mediation analysis, we again found evidence of inconsistency between the results of the two analytic strategies: Although removing the communication of peer inefficacy was associated with increased distress $\left(M_{\text {diff. }}=\right.$ 0.75), this effect could not be explained by recipients reports of engaging in less upward comparison. There was no difference in the average use of upward social comparison between the two conditions $\left(M_{\text {diff. }}=0.003\right), t(142)=0.00, p=.992$.

It is surprising that upward social comparison did not mediate the effect of the invisible support conditions. Having seen that upward social comparison predicted increases in distress independently of condition, we did not see the problem as due to unreliability of measurement. It is possible, however, that the two-item measure that focused only on relative knowledge and nervousness did not cover a sufficient range of social comparison dimensions. Furthermore, across all conditions, the mean reported use of upward social comparison was lower than we anticipated, 3.71 on a 0-10 scale, midway between "a little" and "moderately." Given that the confederate (a) presented herself as a peer facing a similar evaluative situation, (b) offered advice in two of the five conditions, and (c) expressed concern about her own performance in only one of the five conditions, one might reasonably have ex- pected her to evoke a higher level of upward comparison overall. It seems that further evidence is necessary before any firm conclusions can be drawn regarding social comparison as a mediator.

Summary. The aim of Study 3 was to use both experimental and statistical control techniques to investigate potential mediators of visibility and invisibility effects. Three noteworthy patterns emerged. First, the experimental analysis (a) replicated the detrimental effect of visible support found in Study 2 and (b) showed that removing the inefficacy communication undid the effect. The statistical mediation analysis confirmed this interpretation. Second, the experimental analysis replicated the beneficial effect of invisible support found in Study 2, and removing the communication of the provider's inefficacy appeared to eliminate this effect. However, the mediational analysis did not show that a reduction in upward social comparison accounted for this effect. Rather, it revealed that reduced appraisals of inefficacy partly accounted for it. Taken together, the analyses indicated the central mediational role of reflected appraisals of inefficacy in explaining both the deleterious effect of visibility and the beneficial effect of invisibility. Finally, although neither support visibility or invisibility nor support content per se related to stressor reactivity, the constrained nature of these contrasts limit their informativeness.

\section{General Discussion}

It has been more than 3 decades since the role of social relationships in promoting health and psychological functioning emerged as a major topic of research (Stroebe \& Stroebe, 1996). Although the epidemiological evidence for the benefits of social relationships is now considered very strong (see, e.g., the classic review by House, Landis, \& Umberson, 1988), the social psychological processes that mediate these effects remain unclear. In particular, it has proven difficult to show that supportive social interactions play a beneficial role. To explain this inconsistency, Bolger et al. (2000) suggested that support recipients may not be able to give accurate accounts of the support they receive and that a considerable number of supportive interactions occur "under the radar" and are not interpreted as support.

In the current article, we continued this line of research and reported the results of three experiments designed to investigate the effectiveness of support visibility in promoting adjustment to a significant stressor. The prior field research by Bolger et al. (2000) and Shrout et al. (2006) found evidence suggesting that invisible support, that is, interactions coded by the provider as support but not by the recipient, were effective in promoting adjustment, whereas visible support left recipients at best no better off than if they had received no support. Broadly speaking, the results of these experiments served to confirm the findings of the earlier field research. Across the three experiments, supportive behaviors by confederate peers that were accomplished without the recipients' awareness were the most effective in lowering emotional reactivity to a significant stressor. Visible support, by contrast, appeared to be detrimental to adjustment or, at best, ineffective.

Explanatory analyses conducted in Experiment 3 demonstrated the crucial mediational role of the recipients' appraisal that the supportive peer viewed them as inefficacious. This reflected appraisal was important in explaining both the benefits of invisible support and the costs of visible support. Support attempts that avoided evoking this appraisal in recipients were more likely to be beneficial than those that did not; support attempts that evoked this 
appraisal were more likely to be detrimental than those that did not. Thus, it appears that invisibility per se is not the essence of what makes invisible support effective; rather, it is (at least in part) avoiding the communication that the support recipient is inefficacious.

It is important to consider whether these results - the detrimental effects of visible support in particular-are due to the visible support behaviors being viewed as inappropriate or insulting by participants. It is well known that naturally occurring support attempts may be miscarried in such ways (Coyne et al., 1988; Lehman, Ellard, \& Wortman, 1986; Lehman \& Hemphill, 1990), and more generally, evidence is accumulating that for supportive acts to be effective they must be tailored to the needs of the recipient (Cutrona \& Cole, 2000; Cutrona \& Russell, 1990). Furthermore, research has shown that negative social interactions are common in most interpersonal relationships (Rook, 1984, 1990a, 1998; Rook \& Pietromonaco, 1987). Our manipulation checks and recipient ratings of provider supportiveness, however, do not sustain this interpretation. It appears that recipients regarded the provider's behaviors as well intentioned and helpful.

If invisible or indirect support is a common occurrence in daily life, does this mean that people are blissfully unaware of the benefits they receive from others? Although this could be viewed as an implication of our findings, we caution against it. Whether in a peer context or in the context of family and intimate relationships, we think it is likely that people know in a global sense that they are supported even if they appear unaware of the details of the support they receive. For example, supportive interactions that recipients do not code as support may nevertheless be coded as positive experiences (e.g., if a spouse deliberately frames her partner's upcoming job demands in a positive light), and partners who are skilled in this way will be valued by the recipients. There is reason to think, however, that people may also take the benefits of their relationships for granted. Berscheid (1983) argued that this can be the case particularly in close relationships in which through coordinated, routine behavior (e.g., cooking, cleaning, child care) partners enable one another to accomplish daily goals in an emotionally quiescent way.

\section{Unresolved Issues}

Although the research reported here has provided further evidence for the efficacy of invisible support, it leaves a number of important issues unresolved.

Is the content of the supportive interaction important? The social support literature typically distinguishes at least two types of supportive content, emotional and instrumental (House, Kahn, McLeod, \& Williams, 1985; Reis \& Collins, 2000; Wills \& Shinar, 2000). In all three studies we explicitly included content designed to be supportive in the context of a speech stressor. In Studies 1 and 3 providers conveyed instrumental content, that is, advice on public speaking; in Study 2 they conveyed emotional content, that is, the belief that the participant would "do fine." Although we know from the manipulation checks that participants (in the visible conditions) registered the content of the interactions, our oneadmittedly suboptimal - test failed to confirm that the content of the support, advice on public speaking, had any beneficial effect on distress immediately prior to when participants expected to give their speech. Furthermore, because participants did not in fact give a speech, we were unable to see whether the quality of the speech was better in those conditions in which advice on public speaking was conveyed.

How important is the support provider's intention to be supportive? In the current studies, confederates in the basic invisible conditions-who like all confederates were blind to the study's hypotheses-were not given the intention to be supportive. Rather their task was to act out a script in which they presented themselves as feeling inefficacious and in need of help. Yet, as we have seen, the basic invisible conditions were the most effective in promoting adjustment. Although we believe that skillful support providers may use this strategy intentionally, this does not appear to be essential. It may also be the case that skillful providers provide help in this way without realizing that they are being helpful. As such, this kind of unintentional, unreflective help is difficult to pin down in field studies and even in lab studies that use supporters who have existing relationships with the participant (Bolger et al., 2000; Coyne \& Bolger, 1990). It should be noted that previous findings on the benefits of companionship in close relationships (Rook, 1987, 1990b) may be due in part to behaviors that neither providers nor recipients would regard as explicitly supportive.

Is visible support ineffective for all emotions? We have shown that visible support is, overall, ineffective in preventing stressrelated negative emotions. Obviously, negative emotions are the most relevant emotions to stress reactivity, but this does not mean that positive emotions are similarly effected. We have evidence from diary work that visible support appears to boost feelings of intimacy in couples (Gleason et al., 2003), and indeed we have seen in Study 3 that confederates are rated positively in the visible support conditions (see also Hagedoorn et al., 2000). Finally, the beneficial indirect effect of the Visible B condition in Study 3 suggests the possibility that further modifications of this condition, ones that eliminate its possible communication of presumptuousness, could result in an overall beneficial effect.

What if support is requested? As Figure 1 indicates, an important boundary condition for the effects discussed here are situations in which support is requested. Sequential accounts of support interactions often identify support requests as important initiating events (e.g., Cutrona, 1996; Jung, 1987). However, such situations are clearly different from those studied in these experiments and also- - by definition - from the invisible support interactions identified in prior diary studies. When an individual requests support, it is apparent that he or she has already appraised the situation to be beyond his or her capacity to deal with it unaided. Thus, the support interaction, if it occurs, will not necessarily increase the recipient's feelings of inefficacy, feelings that are known to increase distress. Requested support may, of course, be detrimental for other reasons, such as if it is given grudgingly or in an insulting manner (Coyne et al., 1988).

The issue of whether support visibility interacts with support requests is, we believe, a major issue for future research. We hypothesize that skillful support providers know that direct, visible support can have unintended costs at early, prerogatory stages in a stress process, whereas such support is expected and welcome at postrogatory stages, when recipients have concluded that they need help from others. Additional field and laboratory studies of support processes will be necessary to confirm this hypothesis.

The continuing puzzle of perceived versus enacted support. Although the current research provides evidence that received or enacted support can promote adjustment to stressors, the relation- 
ship between these subtle if not invisible acts and generalized perceptions of available support remains unclear. We noted earlier that it is premature to conclude that people are generally unaware of the benefits they receive from their social networks and personal relationships. Nevertheless, as shown in the current article, social interactions that are demonstrably bad for the recipient are nonetheless perceived as supportive, and this blatant inconsistency needs to be understood if researchers are to fathom the relationship between support at the level of general perceptions and support at the level of interpersonal behavior.

\section{Conclusions and Implications}

Although most theories of social support effects posit explanatory processes involving social interaction, the evidence for such processes has been surprisingly weak. In the current experimental studies we have pursued one explanation for this situation, namely, that supportive acts that are accomplished in subtle, unobtrusive, and, to the recipient, invisible ways, tend to be more effective than explicit, visible support. In addition, we have shown that a key reason why invisible support is beneficial is that it avoids communicating to recipients that they are inefficacious. Thus fieldwork suggests that support visibility matters in real-world settings, and given the present experimental evidence, one can be more confident that these associations reflect a causal process. In conclusion, therefore, the evidence presented above bolsters the idea that support that does not draw attention to itself or to the support recipient is particularly effective in helping people cope with important life stressors.

\section{References}

Abraido-Lanza, A. F. (2004). Social support and psychological adjustment among Latinas with arthritis: A test of a theoretical model. Annals of Behavioral Medicine, 27, 162-171.

Baron, R. M., \& Kenny, D. A. (1986). The moderator-mediator variable distinction in social psychological research: Conceptual, strategic, and statistical considerations. Journal of Personality and Social Psychology, $51,1173-1182$.

Barrera, M., Jr. (1986). Distinctions between social support concepts, measures, and models. American Journal of Community Psychology, 14, 413-445.

Baumeister, R. F., \& Leary, M. R. (1995). The need to belong: Desire for interpersonal attachments as a fundamental human motivation. Psychological Bulletin, 117, 497-529.

Berkman, L. F. (1995). The role of social relations in health promotion. Psychosomatic Medicine, 57, 245-254.

Berkman, L. F., Glass, T., Brissette, I., \& Seeman, T. E. (2000). From social integration to health: Durkheim in the new millennium. Social Science and Medicine, 51, 843-857.

Berscheid, E. (1983). Emotion. In H. H. Kelley, E. Berscheid, A. Christensen, J. H. Harvey, T. L. Huston, G. Levinger, et al. (Eds.), Close relationships (pp. 110-168). New York: W. H. Freeman.

Bolger, N., \& Eckenrode, J. (1991). Social relationships, personality, and anxiety during a major stressful event. Journal of Personality and Social Psychology, 61, 440-449.

Bolger, N., Zuckerman, A., \& Kessler, R. C. (2000). Invisible support and adjustment to stress. Journal of Personality and Social Psychology, 79, 953-961.

Bowlby, J. (1969). Attachment and loss: Vol. 1: Attachment. New York: Basic Books.

Brewer, M. B. (2000). Research design and issues of validity. In H. T. Reis \& C. M. Judd (Eds.), Handbook of research methods in social and personality psychology (pp. 3-16). New York: Cambridge University Press.

Buunk, B. P., \& Hoorens, V. (1992). Social support and stress: The role of social comparison and social exchange processes. British Journal of Clinical Psychology, 31, 445-457.

Carnegie, D. (1990). The quick and easy way to effective public speaking. New York: Pocket/Simon \& Schuster.

Clark, M. S., \& Mills, J. (1979). Interpersonal attraction in exchange and communal relationships. Journal of Personality and Social Psychology, $37,12-24$.

Cohen, J. (1988). Statistical power analysis for the behavioral sciences (2nd ed.). Mahwah, NJ: Erlbaum.

Cohen, J., Cohen, P., West, S. G., \& Aiken, L. S. (2003). Applied multiple regression/correlation analysis for the behavioral sciences (3rd ed.) Mahwah, NJ: Erlbaum.

Cohen, S. (1992). Stress, social support, and disorder. In H. O. F. Veiel \& U. Baumann (Eds.), The meaning and measurement of social support (pp. 109-124). New York: Hemisphere.

Cohen, S., \& Wills, T. A. (1985). Stress, social support, and the buffering hypothesis. Psychological Bulletin, 98, 310-357.

Collins, N. L., Dunkel-Schetter, C., Lobel, M., \& Scrimshaw, S. C. M. (1993). Social support in pregnancy: Psychosocial correlates of birth outcomes and postpartum depression. Journal of Personality and Social Psychology, 65, 1243-1258.

Collins, R. L. (1996). For better or worse: The impact of upward social comparison on self-evaluations. Psychological Bulletin, 119, 51-69.

Cook, T. D., \& Groom, C. (2004). The methodological assumptions of social psychology: The mutual dependence of substantive theory and method choice. In C. Sansone, C. C. Morf, \& A. T. 1. Panter (Eds.), The Sage handbook of methods in social psychology (pp. 19-44). Thousand Oaks, CA: Sage.

Cooley, C. H. (1902/1983). Human nature and the social order. New Brunswick, NJ: Transaction Books.

Coyne, J. C., \& Bolger, N. (1990). Doing without social support as an explanatory concept. Journal of Social and Clinical Psychology, 9, $148-158$.

Coyne, J. C., Wortman, C. B., \& Lehman, D. R. (1988). The other side of support: Emotional overinvolvement and miscarried helping. In B. H. Gottlieb (Ed.), Marshaling social support: Formats, processes, and effects (pp. 305-330). Newbury Park, CA: Sage.

Cranford, J. A., Shrout, P. E., Iida, M., Rafaeli, E., Yip, T., \& Bolger, N. (2006). A procedure for evaluating sensitivity to within-person change: Can mood measures in diary studies detect change reliably? Personality and Social Psychology Bulletin, 32, 917-929.

Cronbach, L. J., \& Furby, L. (1970). How should we measure "change"-or should we? Psychological Bulletin, 74, 68-80.

Cutrona, C. E. (1996). Social support in couples: Marriage as a resource in times of stress. Thousand Oaks, CA: Sage.

Cutrona, C. E., \& Cole, V. (2000). Optimizing support in the natural network. In S. Cohen, L. G. Underwood, \& B. H. Gottlieb (Eds.), Social support measurement and intervention: A guide for health and social scientists (pp. 278-308). New York: Oxford University Press.

Cutrona, C. E., \& Russell, D. W. (1990). Type of support and specific stress: Toward a theory of optimal matching. In B. R. Sarason, I. G. Sarason, \& G. R. Pierce (Eds.), Social support: An interactional view (pp. 319-366). New York: Wiley.

Derlega, V. J., Barbee, A. P., \& Winstead, B. A. (1994). Friendship, gender, and social support: Laboratory studies of supportive interactions. In B. R. Burleson, T. L. Albrecht, \& I. G. Sarason (Eds.), Communication of social support: Messages, interactions, relationships, and community (pp. 136-151). Thousand Oaks, CA: Sage.

Dunkel-Schetter, C., \& Bennett, T. L. (1990). Differentiating the cognitive and behavioral aspects of social support. In B. R. Sarason, I. G. Sarason, \& G. R. Pierce (Eds.), Social support: An interactional view (pp. 267-296). New York: Wiley. 
Feldman, S. I., Downey, G., \& Schaffer-Neitz, R. (1999). Pain, negative mood, and perceived support in chronic pain patients: A daily diary study of people with reflex sympathetic dystrophy syndrome. Journal of Consulting and Clinical Psychology, 67, 776-785.

Fisher, J. D., Nadler, A., \& Whitcher-Alagna, S. (1982). Recipient reactions to aid. Psychological Bulletin, 91, 27-54.

Frazier, P. A., Tix, A. P., \& Barnett, C. L. (2003). The relational context of social support: Relationship satisfaction moderates the relations between enacted support and distress. Personality and Social Psychology Bulletin, 29, 1133-1146.

Gleason, M. E. J., Iida, M., Bolger, N., \& Shrout, P. E. (2003). Daily supportive equity in close relationships. Personality and Social Psychology Bulletin, 29, 1036-1045.

Hagedoorn, M., Kuijer, R. G., Buunk, B. P., DeJong, G., Wobbes, T., \& Sanderman, R. (2000). Marital satisfaction in patients with cancer: Does support from intimate partners benefit those who need it most? Health Psychology, 19, 274-282.

Helgeson, V. S. (1993). Two important distinctions in social support: Kind of support and perceived versus received. Journal of Applied Social Psychology, 23, 825-845.

Hobfoll, S. E., \& Vaux, A. (1993). Social support: Social resources and social context. In L. Goldberger \& S. Breznitz (Eds.), Handbook of stress: Theoretical and clinical aspects (2nd ed., pp. 685-705). New York: Free Press

House, J. S., Kahn, R. L., McLeod, J. D., \& Williams, D. (1985). Measures and concepts of social support. In S. Cohen \& S. L. Syme (Eds.), Social support and health (pp. 83-108). San Diego, CA: Academic Press.

House, J. S., Landis, K. R., \& Umberson, D. (1988, July 29). Social relationships and health. Science, 241, 540-545.

House, J. S., Umberson, D., \& Landis, K. R. (1988). Structures and processes of social support. Annual Review of Sociology, 14, 293-318.

Hoyle, R. H., \& Robinson, J. C. (2004). Mediated and moderated effects in social psychological research: Measurement, design, and analysis issues. In C. Sanson, C. C. Morf, \& A. T. Panter (Eds.), The Sage handbook of methods in social psychology (pp. 213-233). Thousand Oaks, CA: Sage.

Jung, J. (1987). Toward a social psychology of social support. Basic and Applied Social Psychology, 8, 57-83.

Kenny, D. A., Kashy, D. A., \& Bolger, N. (1998). Data analysis in social psychology. In D. T. Gilbert, S. T. Fiske, \& G. Lindzey (Eds.), The handbook of social psychology (4th ed., Vol. 1, pp. 233-265). New York: McGraw-Hill.

Kutner, M. H., Nachtsheim, C. J., Neter, J., \& Li, W. (2005). Applied linear statistical models (5th ed.). Boston: McGraw-Hill/Irwin.

Lakey, B., \& Drew, J. B. (1997). A social-cognitive perspective on social support. In G. R. Pierce \& B. Lakey (Eds.), Sourcebook of social support and personality (pp. 107-140). New York: Plenum Press.

Leatham, G., \& Duck, S. (1990). Conversations with friends and the dynamics of social support. In S. Duck (Ed.), Personal relationships and social support (pp. 1-29). London: Sage.

Lehman, D. R., Ellard, J. H., \& Wortman, C. B. (1986). Social support for the bereaved: Recipients' and providers' perspectives on what is helpful. Journal of Consulting and Clinical Psychology, 54, 438-446.

Lehman, D. R., \& Hemphill, K. J. (1990). Recipients' perceptions of support attempts and attributions for support attempts that fail. Journal of Social and Personal Relationships, 7, 563-574.

Lieberman, M. A. (1986). Social supports-The consequences of psychologizing: A commentary. Journal of Consulting and Clinical Psychology, 54, 461-465

Lorr, M., \& McNair, D. M. (1971). The Profile of Mood States manual. San Diego, CA: Educational and Industrial Testing Service.

Martire, L. M., Stephens, M. A. P., Druley, J. A., \& Wojno, W. C. (2002). Negative reactions to received spousal care: Predictors and consequences of miscarried support. Health Psychology, 21, 167-176.

Maxwell, S. E., \& Delaney, H. D. (2004). Designing experiments and analyzing data: A model comparison perspective (2nd ed.). Mahwah, NJ: Erlbaum.

Mills, J. (1976). A procedure for explaining experiments involving deception. Personality and Social Psychology Bulletin, 2, 3-13.

Nadler, A., \& Fisher, J. D. (1986). The role of threat to self-esteem and perceived control in recipient reactions to help: Theory development and empirical validation. In L. Berkowitz (Ed.), Advances in experimental social psychology (Vol. 19, pp. 81-123). New York: Academic Press.

Nadler, A., Fisher, J. D., \& Ben Itzhak, S. (1983). With a little help from my friend: Effect of single or multiple act aid as a function of donor and task characteristics. Journal of Personality and Social Psychology, 44, 310-321.

Newsom, J. T. (1999). Another side to caregiving: Negative reactions to being helped. Current Directions in Psychological Science, 8, 183-187.

Newsom, J. T., \& Schulz, R. (1998). Caregiving from the recipient's perspective: Negative reactions to being helped. Health Psychology, 17, 172-181.

Pierce, G. R., Lakey, B., Sarason, I. G., Sarason, B. R., \& Joseph, H. J. (1997). Personality and social support processes: A conceptual overview. In G. R. Pierce, B. Lakey, I. G. Sarason, \& B. R. Sarason (Eds.), Sourcebook of social support and personality (pp. 3-18). New York: Plenum Press.

Pierce, G. R., Sarason, B. R., \& Sarason, I. G. (1992). General and specific support expectations and stress as predictors of perceived supportiveness: An experimental study. Journal of Personality and Social Psychology, 63, 297-307.

Reis, H. T., \& Collins, N. (2000). Measuring relationship properties and interactions relevant to social support. In S. Cohen, L. G. Underwood, \& B. H. Gottlieb (Eds.), Social support measurement and intervention: A guide for health and social scientists (pp. 136-192). New York: Oxford University Press.

Reis, H. T., Collins, W., \& Berscheid, E. (2000). The relationship context of human behavior and development. Psychological Bulletin, 126, 844872.

Rook, K. S. (1984). The negative side of social interaction: Impact on psychological well-being. Journal of Personality and Social Psychology, 46, 1097-1108.

Rook, K. S. (1987). Social support vs. companionship: Effects on life stress, loneliness, and evaluations by others. Journal of Personality and Social Psychology, 52, 1132-1147.

Rook, K. S. (1990a). Parallels in the study of social support and social strain. Journal of Social and Clinical Psychology, 9, 118-132.

Rook, K. S. (1990b). Social relationships as a source of companionship: Implications for older adults' psychological well-being. In B. R. Sarason, I. G. Sarason, \& G. R. Pierce (Eds.), Social support: An interactional view (pp. 219-250). New York: Wiley.

Rook, K. S. (1998). Investigating the positive and negative sides of personal relationships: Through a lens darkly? In B. H. Spitzberg \& W. R. Cupach (Eds.), The dark side of close relationships (pp. 369393). Mahwah, NJ: Erlbaum.

Rook, K. S., \& Pietromonaco, P. R. (1987). Close relationships: Ties that heal or ties that bind? Advances in Personal Relationships, 1, 1-35.

Seidman, G., Shrout, P. E., \& Bolger, N. (2006). Why is enacted social support associated with increased distress? Using simulation to test two possible sources of spuriousness. Personality and Social Psychology Bulletin, 32, 52-65.

Shrout, P. E., \& Bolger, N. (2002). Mediation in experimental and nonexperimental studies: New procedures and recommendations. Psychological Methods, 7, 422-445.

Shrout, P. E., Herman, C. M., \& Bolger, N. (2006). The costs and benefits of practical and emotional support on adjustment: A daily diary study of couples experiencing acute stress. Personal Relationships, 13, 115-134.

Smith, E. R. (2000). Research design. In H. T. Reis \& C. M. Judd (Eds.), Handbook of research methods in social and personality psychology (pp. 17-39). New York: Cambridge University Press. 
Sobel, M. E. (1982). Asymptotic confidence intervals for indirect effects in structural equation models. In S. Leinhardt (Ed.), Sociological methodology (pp. 290-312). San Francisco: Jossey-Bass.

Sobel, M. E. (1986). Some new results on indirect effects and their standard errors in covariance structure models. In N. Tuma (Ed.), Sociological methodology (Vol. 16, pp. 159-186). Washington, DC: American Sociological Association.

Spencer, S. J., Zanna, M. P., \& Fong, G. T. (2005). Establishing a causal chain: Why experiments are often more effective than mediational analyses in examining psychological processes. Journal of Personality and Social Psychology, 89, 845-851.

Stroebe, W., \& Stroebe, M. (1996). The social psychology of social support. In E. T. Higgins \& A. W. Kruglanski (Eds.), Social psychology: Handbook of basic principles (pp. 597-621). New York: Guilford Press.

Stryker, S., \& Statham, A. (1985). Symbolic interaction and role theory. In G. Lindzey \& E. Aronson (Eds.), Handbook of social psychology (3rd ed., pp. 311-378). Reading, MA: Addison-Wesley.

Taris, T. W. (2000). A primer in longitudinal data analysis. London: Sage.

Taylor, S. E., Buunk, B. P., \& Aspinwall, L. G. (1990). Social comparison, stress, and coping. Personality \& Social Psychology Bulletin, 16, 7489.

Taylor, S. E., Klein, L. C., Lewis, B. P., Gruenewald, T. L., Gurung, R. A. R., \& Updegraff, J. A. (2000). Biobehavioral responses to stress in females: Tend-and-befriend, not fight-or-flight. Psychological Review, 107, 411-429.

Thoits, P. A. (1985). Social support and psychological well-being: Theoretical possibilities. In I. G. Sarason \& B. R. Sarason (Eds.), Social support: Theory, research and applications (pp. 51-72). Dordrecht, the Netherlands: Martinus-Nijhof.

Uchino, B. N., Cacioppo, J. T., \& Kiecolt-Glaser, J. K. (1996). The relationship between social support and physiological processes: A review with emphasis on underlying mechanisms and implications for health. Psychological Bulletin, 119, 488-531.

Uchino, B. N., \& Garvey, T. S. (1997). The availability of social support reduces cardiovascular reactivity to acute psychological stress. Journal of Behavioral Medicine, 20, 15-27.

Wethington, E., \& Kessler, R. C. (1986). Perceived support, received support, and adjustment to stressful life events. Journal of Health and Social Behavior, 27, 78-89.

Wills, T. A. (1991). Social support and interpersonal relationships. In M. S Clark (Ed.), Review of personality and social psychology (Vol. 12, pp. 265-289). Thousand Oaks, CA: Sage.

Wills, T. A., \& Shinar, O. (2000). Measuring perceived and received social support. In S. Cohen, L. G. Underwood, \& B. H. Gottlieb (Eds.), Social support measurement and intervention: A guide for health and social scientists (pp. 86-135). New York: Oxford University Press.

Winstead, B. A., Derlega, V. J., Lewis, R. J., Sanchez-Hucles, J., \& Clarke, E. (1992). Friendship, social interaction, and coping with stress. Communication Research, 19, 193-211.

Received September 9, 2004 Revision received March 28, 2006 Accepted April 20, 2006 